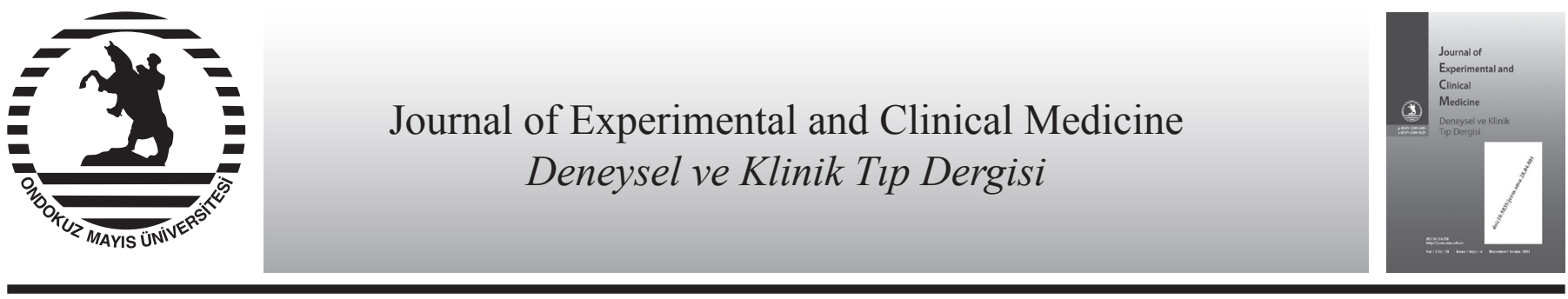

Klinik araştırma / Clinical research

doi: $10.5835 /$ jecm.omu.28.04.007

\title{
Fetal ventrikülomegali ve ventriküler sistemle ilişkili anomalilerin tanısında fetal manyetik rezonans görüntülemenin rolü
}

\author{
The role of fetal magnetic resonance imaging in the diagnosis of fetal ventriculomegaly and ventricular system associated \\ anomalies
}

Tuba Bayrak Uluışık ${ }^{a^{*}}$, Meltem Ceyhana, Lütfi İncesua, Miğraci Tosun ${ }^{\mathrm{b}}$, Erdal Malatyalığlub, Yaşar Tayfun Alper ${ }^{\mathrm{b}}$, Adnan Dağçınarc

${ }^{a}$ Ondokuz Mayıs Üniversitesi Tıp Fakültesi Radyoloji Anabilim Dalı, Samsun

${ }^{b}$ Ondokuz Mayıs Üniversitesi Tıp Fakültesi Kadın Hastalıkları ve Doğum Anabilim Dalı, Samsun

cOndokuz Mayıs Üniversitesi Tıp Fakültesi Nöroşirurji Anabilim Dalı, Samsun

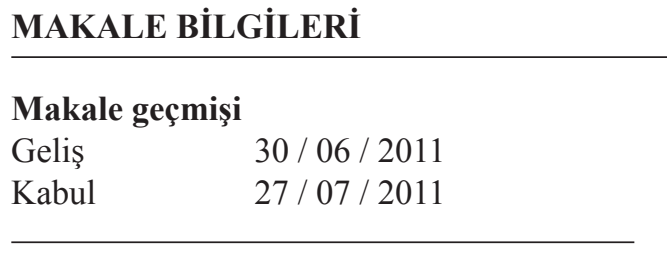

\section{* Yazışma Adresi:}

Tuba Bayrak Uluışı

Bahçelievler mah. 291.sk. Bülent Kırca Apt.

No: 15 Kat:3 Daire: 6, Ordu

E-posta: tubabayrak82@hotmail.com

\section{Anahtar Kelimeler:} \\ Apopitoz \\ Fetal \\ Fetal MRG \\ Manyetik rezonans görüntüleme \\ Prenatal \\ Proliferasyon \\ Ultrasonografi \\ Ventrikülomegali
}

\section{Keywords:}

Apoptosis

Fetal

Fetal MRI

Magnetic resonance imaging

Prenatal

Proliferation

Ultrasonography

Ventriculomegaly

\section{ÖZET}

Bu çalışmada ultrasonografik olarak ventrikülomegali (VM) ve ventriküler sistemle ilişkili anomali (VSİA) saptanan veya şüphelenilen olgularda etyolojiye yönelik değerlendirmenin ve ayırıcı tanının yapılabilmesi, eşlik eden diğer santral sinir sistemi (SSS) anomalilerinin saptanabilmesi amacıyla veya ultrasonografi (US) tetkikinin yetersiz kaldığ durumlarda fetal manyetik rezonans görüntülemenin (MRG) rolünün araştırılması amaçlanmıştır. Haziran 2008 - Ocak 2011 tarihleri arasında obstetrik ultrasonografi ile fetal VM ve VSİA ya da şüphesi bulunan 80 gebeye ( 80 fetus) uygulanan fetal MRG tetkikleri retrospektif olarak değerlendirilmiştir. Çalışmaya alınan kadınların yaşları 17-45 yıl arasında (ortalama 27 yaş) değişmektedir. Son menstruasyon tarihine göre belirlenen gebelik haftaları 18 -35 gestasyonel haftalar (ortalama 25 hafta) arasındadır. Çalışmamızda fetal MRG; izole VM ( $\mathrm{n}=39)$, kombine VM $(\mathrm{n}=6)$, mega sisterna magna $(\mathrm{n}=11)$, kolposefali, korpus kallozum agenezisi şüphesi $(n=9)$, Dandy Walker Malformasyonu/Varyantı $(n=9)$, 4.ventrikül dilatasyonu $(n=2), 3$. ventrikül dilatasyonu $(n=3)$, monoventrikül, holoprozensefali $(n=3)$, meningomyelosel $(n=2)$ endikasyonları nedeniyle uygulanmıştı. Ayrıca üç hastada morbid obeziteye bağlı US değerlendirmenin yetersizliği ve bir hastada lateral ventriküllerin US olarak değerlendirilememesi nedeniyle fetal MRG tetkiki uygulanmış olup US'nin limitasyonlarını göstermek açısından çalışmaya dahil edilmiştir. Fetal MRG, 23 olguda $(\%$ 28,75) tanıda değişikliğe yol açmış, 28 olguda (\% 35) ek bulgu tesbit etmiştir. Olguların 29'unda (\% 36,25) MRG, US ile konulan ön tanıyı doğrulamış, ek anomali saptamamış ancak daha fazla anatomik detay sağlamıştır. Fetal MRG, yüksek kontrast çözünürlüğü ile fetal beynin değerlendirilmesinde normal gelişim hakkında daha spesifik bilgiler verebildiği gibi fetal ventrikülomegali ve VSİA varlığında US'den çok daha fazla anatomik detay ve bilgi sağlayabilmekte, gebeliklerin yönlendirilmesine önemli katk1larda bulunabilmektedir.

J. Exp. Clin. Med., 2011; 28:155-161

\section{ABSTRACT}

In this study, in patients who ventriculomegaly (VM) and the ventricular system associated anomalies with detected or suspected with ultrasonography, etiology and differential diagnosis can be made for the assessment, accompanied with other central nervous system (CNS) abnormalities, or ultrasound (US) to detect the anomalies of inadequate, aimed to investigate the role of fetal magnetic resonance imaging (MRI).

Magnetic resonance imagines and reports that were applied to 80 pregnant women who have fetal ventriculomegaly and ventricular system associated anomalies or suspected anomaly after US between July 2008 and January 2011 were retrospectively evaluated. The ages of women in the study ranged from 17 to 45 (mean 27). Gestational age determined by date of last menstruation was between 18 -35 weeks of gestation (mean 25 weeks). In our study, fetal MRI was performed because of isolated VM ( $n=39)$, combined 
VM ( $n=6)$, mega cisterna magna $(n=11)$, colpocephaly, suspicion of corpus callosum agenesis ( $n=9)$, Dandy-Walker malformation/variant $(n=9)$, dilation of the fourth ventricle $(n=2)$, dilation of the third ventricle $(n=3)$, monoventricle, holoprosencephaly $(n=3)$, meningomyelocel $(n=2)$ indications. Also, US was not performed in three patients because of morbid obesity, and lateral ventricles couldn't evaluated in one patient. MRI was performed in these patients and included in the study for showing the limitations of US. Fetal MRI changed the diagnosis in 23 cases $(28.75 \%)$ and detected additional findings in 28 cases (35\%). MRI confirmed the pre-diagnosis with US in 29 cases $(36.25 \%)$, additional anomalies were not detected but more anatomical detail was provided. Fetal MRI, with high contrast resolution, can provide more specific information about the normal development in the evaluation of fetal brain and more anatomical detail and information in the presence of fetal ventriculomegaly and ventricular system associated anomalies and also provide contributions to directing pregnancies.

J. Exp. Clin. Med., 2011; 28:155-161

C 2011 OMÜ Tüm hakları saklıdır

\section{Giriş}

Ventriküler sistemle ilişkili anomaliler (VSİA), geniş bir alanı kapsamakla beraber en sık olarak ventrikülomegali (VM) şeklinde karşımıza çıkmaktadır. Ventrikülomegali çoğunlukla lateral ventriküllerde görülür ve serebral ventrikül genişliklerinin atrium düzeyinden yapılan ölçümlerde 10 milimetre $(\mathrm{mm})$ ve üzerinde olmasıdır (Cardoza ve ark., 1988; Heiserman ve ark., 1991; Twickler ve ark., 2002).

Ventrikülomegali; ek anomalilerin varlığına göre kombine veya izole VM, tarafina göre bilateral, unilateral veya atrial boyutlarda 2 mm'den fazla fark olduğunda asimetrik VM, ventrikül genişliğine göre hafif, orta, ağır VM olarak alt gruplara ayrılmaktadır.

Son yıllarda anomali taraması için ultrasonografinin (US) yaygın olarak kullanılmasıyla VM olguları içinde izole VM görülme oranını \%50 olarak saptayan yayınlar bulunmaktadır (Zimmerman ve Bilaniuk, 2005; Cavalcanti ve Salamao, 2003).

Fetal santral sinir sistemi (SSS) ve VSİA'nın değerlendirilmesinde temel görüntüleme yöntemi prenatal ultrasonografi olmakla beraber US kullanılarak lezyonların tam karakterizasyonu veya eşlik eden anomalilerin tanımlanması her zaman mümkün değildir (Rich ve ark., 2007). Bu nedenle günümüzde US'de VM ve VSİA saptanan hastalarda, neden olan SSS anomalilerini saptamada fetal MRG yönteminin kullanılması önerilmektedir.

Çalışmamızın amacı; obstetrik ultrasonografide VM ve VSİA olduğu düşünülen veya şüphelenilen gebeliklerde, teşhis, ayırıcı tanı, prognoz ve gebeliğin yönlendirilmesinde noninvaziv ileri teknik bir görüntüleme yöntemi olan fetal MRG tetkikinin retrospektif olarak etkinliğini araştırmaktır.

\section{Gereç ve yöntem}

Çalışmamız O.M.Ü Tıp Fakültesi Tıbbi Araştırma Etik Komisyonu tarafindan değerlendirilmiş olup 30.12.2010 tarih ve 384 sayılı kararı ile yapılması uygun bulunarak onaylanmıştır.

Haziran 2008-Ocak 2011 tarihleri arasında obstetrik US sonucunda tespit edilen veya şüphelenilen fetal VM ve VSİA'nın doğrulanması, etyolojinin saptanması, ayırıcı tanının yapılabilmesi ve eşlik eden diğer SSS anomalilerinin değerlendirilebilmesi amacıyla veya US tetkikinin yetersiz kaldığ 1 durumlarda (posterior fossa değerlendirilmesi, oligohidroamniyoz, ileri gebelik haftalarında kemik yapılardaki akustik gölge artefaktı, uygunsuz fetal pozisyon, maternal obezite vb.) değerlendirme için 80 gebeye (80 fetus), Ondokuz Mayıs Üniversitesi Radyo- loji Anabilim Dalı'nda uygulanan fetal MRG tetkiki retrospektif olarak değerlendirilmiştir.

Gebelik haftası 18 hafta ve altı olan kadınlara bölümümüzde fetal MRG tetkiki uygulanmadığından çalışmaya dahil edilen tüm gebelerin gestasyonel haftası 18 hafta üzerindedir. Fetal hareketler nedeniyle optimal görüntü elde edilememiş olan gebeler çalışmaya alınmamıştır.

MRG, 1,5T alan gücünde manyetik rezonans sistemi (Siemens Magnetom Symphony; Erlangen Germany) ve 6 kanallı body coil ile yapılmıştır. Hastaların MR görüntüleri iki radyolog tarafindan değerlendirilmiştir. MRG tetkiki, T2 ağırlıklı sekanslarda; TRUFI sekansında (True FISP $=$ fast imaging with steady state precession $)\left(\mathrm{TR}=4,7 ; \mathrm{TE}=2,3 ; \mathrm{FA}=58^{\circ}, \mathrm{FoV}=250\right.$, Matrix $=460 \times 512$, kesit kalınlığı $=3-4 \mathrm{~mm}, 6$ kanallı body coil), HASTE sekansinda $\left(\mathrm{TR}=1100 ; \mathrm{TE}=119 ; \mathrm{FA}=150^{\circ} ; \mathrm{FoV}=100\right.$, Matrix $=218 \times 256,6$ kanallı body coil) uygulanmıştır.

Tl ağırlıklı sekans olarak nefes tutturmalı FLASH (fast low angle shot $)\left(\mathrm{TR}=108 ; \mathrm{TE}=4,76 ; \mathrm{FA}=70^{\circ} ; \mathrm{FoV}=500\right.$, Matrix $=192 \times 256$, 6 kanallı body coil) uygulanmıştır. Kesitler arası boşluk bırakılmaksızın fetal boyuta göre 20-45 arasında, 3-4mm kalınlıkta kesitler elde edilmiştir. Fetal pozisyon için, TRUFI sekansında referans görüntüler elde edilmiş olup fetal SSS'e yönelik görüntüler HASTE sekansında aksiyel, koronal ve sagittal olmak üzere üç planda, T1 ağırlıklı görüntüler aksiyel veya koronal planda elde edilmiştir. Fetusa kontrast madde ya da sedatizasyon uygulanmamıştır.

VM derecesi, US'de olduğu gibi lateral ventrikül atrium düzeyindeki en büyük genişlikten ölçülerek hesaplanmıştır. Tanı, bu ölçümün 10 mm ve üzeri olması ile konulmuş olup 10-12 mm arasinda ise hafif VM, 12,1-14,9 $\mathrm{mm}$ arasinda ise ve $3 \mathrm{~mm}$ 'den fazla kortikal kalınlık bulunuyorsa orta dereceli VM, $>15 \mathrm{~mm}$ ve 2 mm'den az kortikal kalınlık varsa şiddetli (ağır) VM olarak değerlendirilmiştir.

\section{Sonuçar}

Haziran 2008-Ocak 2011 tarihleri arasında fetal MRG tetkiki uygulanan 80 gebe (80 fetus) çalışmaya dahil edilmiştir. Çaışmaya alınan kadınların yaşları 17-45 yıl arasında değişmekte (ortalama 27 yaş) olup son menstruasyon tarihine göre belirlenen gebelik haftaları 18-35 gestasyonel haftalar (ortalama 25 hafta) arasındadır.

Çalışmaya dahil edilen olguların fetal MRG endikasyonları ve olgu sayıları Tablo 1' de özetlenmiştir. 
Tablo 1. Çalışmaya dahil edilen hastalarda fetal MRG endikasyonları ve olgu sayıları

\begin{tabular}{|l|l|l|l|}
\hline Fetal MRG endikasyonları & Olgu sayısı (n) & $\begin{array}{l}\text { Fetal MRG } \\
\text { endikasyonları }\end{array}$ & $\begin{array}{l}\text { Olgu sayısı } \\
(\mathbf{n})\end{array}$ \\
\hline İole VM & 39 & $\begin{array}{l}\text { 4.ventrikül } \\
\text { dilatasyonu }\end{array}$ & 2 \\
\hline Kombine VM & 6 & $\begin{array}{l}\text { 3. ventrikül } \\
\text { dilatasyonu }\end{array}$ & 3 \\
\hline $\begin{array}{l}\text { Mega sisterna magna } \\
\text { Kolposefali, KK agenezisi } \\
\text { şüphesi }\end{array}$ & 9 & Monoventrikül,HPE & 3 \\
\hline $\begin{array}{l}\text { Dandy Walker } \\
\text { Malformasyonu/Varyantı }\end{array}$ & 9 & Meningomyelosel & 2 \\
\hline
\end{tabular}

KK: Korpus kallozum, HPE: Holoprozensefali

Fetal MRG, 23 olguda tanıda değişikliğe yol açmış (\% $28,75)$ olup bunların 8 tanesinde ilaveten ek bulgular da tesbit etmiştir. Dandy Walker Malformasyonu (DWM) ön tanılı 6 olgunun 4'ünde tanıda değişikliğe neden olmuş, birinde DWM olmadığını, 3'ünde ise Dandy Walker Varyant (DWV) varlığını göstermiş, DWV saptanan bu 3 olgunun 2'sinde ek bulgular tesbit etmiştir. Kolposefali / KK agenezisi ön tanılı 9 olgunun 2'sinde normal olduğunu göstermiş, bunların birinde ilaveten unilateral orta dereceli VM saptamıştır. Dandy Walker malformasyonu, KK agenezisi ve ek bulguların izlendiği bir olgu Şekil 1'de gösterilmiştir.

Fetal MRG ile ek bulgu saptanan 28 olgunun (\%35), 8'i tanıya ek bulgular olup bunların 2 tanesinde beraberinde VM derecesinde değişikliğe neden olmuştur.

Tablo 2. VM ön tanılı olguların derecelerine göre US ve fetal MRG sonuçları

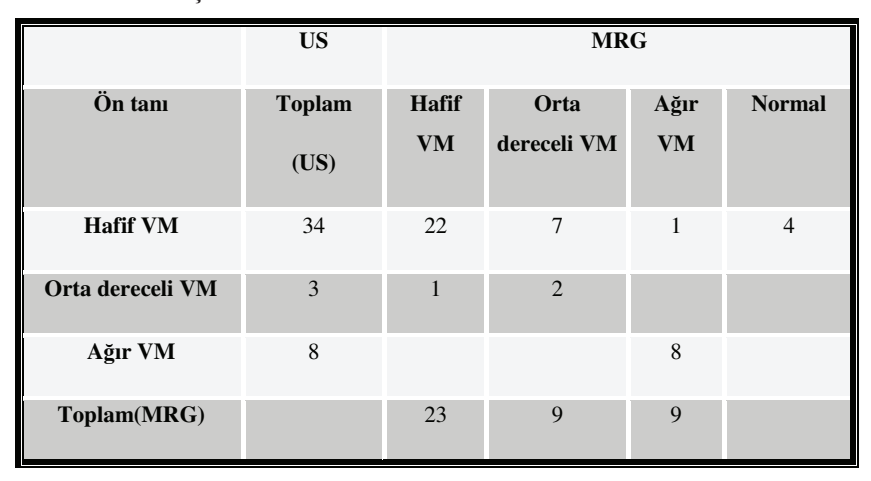

Tablo 3. Obstetrik US ve fetal MRG'de VM derecelerine göre olgu sayıları ve yüzdeleri

\begin{tabular}{|c|c|c|c|c|}
\hline Ön tanı & \multicolumn{2}{|c|}{ US } & \multicolumn{3}{c|}{ MRG } \\
\hline & Olgu Sayısı (n) & $\%$ & Olgu Sayısı (n) & $\%$ \\
\hline Hafif VM & 34 & 75,5 & 23 & 56,1 \\
\hline $\begin{array}{c}\text { Orta dereceli } \\
\text { VM }\end{array}$ & 3 & 6,6 & 9 & 21,9 \\
\hline $\begin{array}{c}\text { Ağır VM } \\
\text { Toplam }\end{array}$ & 8 & 17,9 & 9 & 21,9 \\
\hline \hline
\end{tabular}

Tablo 4. Fetal MRG ile VM tanısı almış $(n=41)$ olgularda Fetal MRG ile saptanan ek bulgu, VM derece ve taraf değişikliklerinin gösterimi

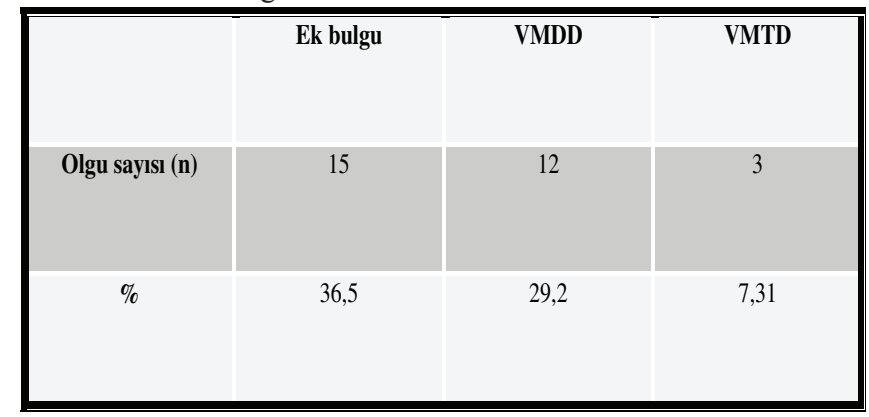

VMDD: Ventrikülomegali derecesinde değişiklik, VMTD: Ventrikülomegali tarafında değişiklik

VM ön tanısıyla fetal MRG çekilen 45 olgunun US ve MRG bulguları Tablo 2, 3 ve 4 'de özetlenmiştir.

VM ön tanısıyla gönderilen olgularda sonografik olarak saptanan izole VM $(n=39)$, kombine VM $(n=6)$ iken fetal MRG ile saptanan izole VM $(n=25)$, kombine VM $(n=16)$ olarak bulunmuştur. Bu da göstermektedir ki; fetal MRG ile ek anomali saptanma oranı US'den daha yüksektir (Tablo 5). İzole ve kombine VM örnekleri Şekil 2 ve 3 'de gösterilmektedir. Ayrıca izole VM ön tanılı 1 olguda US’de saptanamayan mikroftalmi ve afaki tesbit edilmiştir (Şek. 4).

Tablo 5. Obstetrik US ve fetal MRG ile saptanan izole ve kombine VM olguları

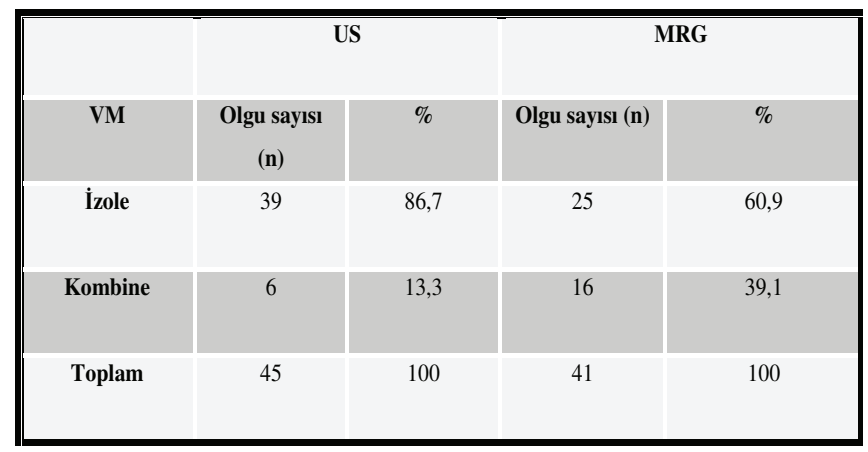

Obezite nedeniyle değerlendirilemeyen 4 olguda normal bulgular saptanmıştır. US ile MRG bulguları, 29 olguda uyumlu olarak raporlanmış (\% 36,25), ek anomali saptanmamıştır. Ancak MRG sahip olduğu daha yüksek kontrast ve geometrik rezolüsyonu sayesinde ekstra anatomik detay sağladığından anomalilerin daha net vizualizasyonunu sağlamiştir.

Çalışmaya aldığımız 80 olgudan 46'sı takiplerine dış merkezde devam ettiğinden bilgilerine ulaşılamamış olup bu olgularda nihai sonuç MRG sonucu olarak kabul edilmiştir. Takipleri hastanemizde yapilan 34 olgunun 9'una terminasyon uygulanırken gebeliğin devamına karar veren 3 olgu postnatal exitus ile sonuçlanmıştır. Terminasyon uygulanan olgulardan yalnızca 1 tanesi patolojik incelemeye izin vermiş olup patoloji sonucu MRG bulgularımızı doğrulamıştır. Terminasyon uygulanan diğer olgular patolojik incelemeyi kabul etmemiştir. Ayrıca terminasyonu kabul etmeyen iki olguda fetal MRG bulguları postnatal MRG ile, 1 olguda operasyon sonucu ile 1 olguda da postnatal klinik ve fizik muayene bulguları ile doğrulanmıştır. Bir olgu ise doğumu hastanemizde 
gerçekleştirmekle beraber düşük APGAR nedeniyle sevk edilmiş olup prognozu bilinmemektedir. İki olgunun ise gebeliği halen devam etmektedir. Çalışmamızın olgu sayılarına göre histogram analizi ile prenatal US ve MRG bulguları Tablo 6 'da özetlenmiştir.

\section{Tartışma}

Santral sinir sistemi anomalileri, intrauterin hayatta en sık karşılaşılan ve gebeliğin gidişatına ve gerekli tedavilere ilişkin kararların alınmasını gerektiren önemli morbidite ve mortalite nedenlerindendir. SSS anomalilerinin tahmini insidans1 100 doğumda birdir (Mc Intosh ve ark., 1954; Myrianthopolus, 1977). Fetal SSS anomalilerinin görüntülenmesinde US, ucuz olması, yaygın kullanım alanı bulması, gebeye ve fetusa bilinen bir zararı olmaması, kolay uygulanabilir ve real time bir inceleme olması nedeniyle ilk ve en sık başvurulan yöntemdir. Ancak anomali saptandığ 1 durumlarda birçok anomalinin nonspesifik görünümde bulunması nedeniyle anomalinin ayrıntılı olarak tanımlanması, fetal anomalinin derecesini değerlendirmek ve eşlik eden ek anomalilerin ortaya çıkarılması her zaman mümkün olamamaktadır. Ayrıca reverberasyon artefaktına bağlı transdusere yakın taraftaki beyin kesimlerinin değerlendirilememesi, geç gestasyon haftalarında ossifikasyon nedeniyle posterior fossanın optimal değerlendirilememesi gibi teknik faktörler yanı sıra fetal pozisyona ve ilerlemiş gebelik yaşına bağlı olarak fetal SSS'nin uygun anatomik planlarda görüntülenememesi, oligohidramnioz ve obezite de incelemenin diğer limitasyonlarını oluşturmaktadır (Levine ve ark., 1997; 1999; 2003; Wang ve ark., 2006).

Manyetik Rezonans Görüntüleme (MRG)'nin, radyasyon içermemesi, multiplanar kesitsel görüntü elde edilebilmesi, çok iyi kontrast rezolüsyonu sağlaması ve özellikle yumuşak doku patolojilerini göstermedeki üstünlüğü yöntemin avantajları arasındadır. Ayrıca MRG'nin uzaysal ve kontrast rezolüsyonu US'den daha yüksektir. US'den farklı olarak oli-

Tablo 6. MRG ve US bulgularına göre gruplar ve her bir gruptaki olgu sayısını gösteren histogram analizi

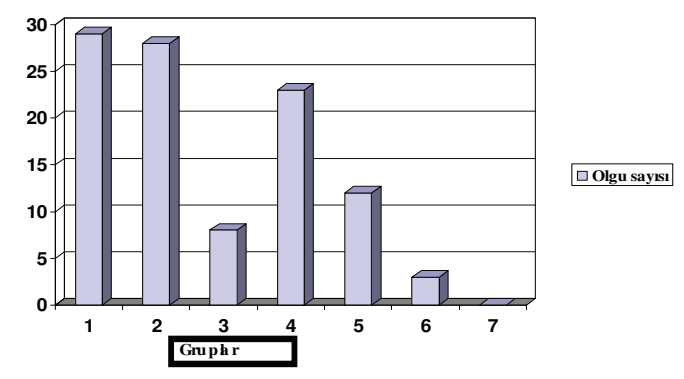

\begin{tabular}{|l|c|c||}
\hline Gruplar & Olgu sayısı & $\%$ \\
\hline 1.MRG = US & 29 & 36,25 \\
\hline 2.MRG ile ek bilgiler & 28 & 35 \\
\hline 3.MRG ile ek bilgiler + tanı değişikliği & 8 & 10 \\
\hline 4.MRG ile tanı değişikliği & 23 & 28,75 \\
\hline 5.MRG ile VM derecesinde değişiklik & 12 & 29,2 \\
\hline 6.MRG ile VM tarafında değişiklik & 3 & 7,31 \\
\hline 7.US'nin MRG'ye sağladı̆ı̆ ek bilgiler & 0 & 0 \\
\hline \hline
\end{tabular}

gohidramniozdan, maternal obeziteden, fetal kraniyal kemik yapılardan ve maternal kemik pelvisten bağımsız olarak görüntü elde eder. Ancak hareketsiz atomlara duyarsız kalmas1, sabit ferromanyetik objelerin (ör.; Implant) artefakt veya çekim için kontrendikasyon (ör.; kardiyak pacemaker, MR uyumsuz protezler) oluşturması, respiratuar, kardiak, peristaltik hareketlere duyarlı olması, klostrofobisi olan hastalarda relatif kontrendikasyon oluşturması, pahalı ve ulaşım imkanlarının kısıtlı oluşu, tetkik süresinin uzun olması ve buna bağlı ileri gebelik haftalarında uzun süreli supin pozisyonda kalma sonucunda vena kava kompresyon sendromu gelişebilmesi yöntemin dezavantajlarıdır (Türk Radyoloji Derneği İzmir Şubesi Eğitim Sempozyumları 2004-2005, Temel Radyoloji Fiziği, İnan Basım, Mayıs 2005, 203). Bütün bunlar birlikte değerlendirildiğinde MRG'nin tarama yöntemi olarak kullanımı önerilmemektedir. Ancak günümüze kadar yapılan çalışmalar fetal SSS anomalilerinin tanısında MRG'nin tanıya önemli katkısı olduğu gibi, tanıyı ve tedaviyi değiştirebilecek bilgiler sağladığını ortaya koymaktadır (Levine ve ark., 1997; 1999; Levine ve Edelman, 1997; Levine, 2001; Whitby ve ark., 2004; Wang ve ark., 2006; Herman-Sucharska ve ark., 2009; Messing-Jünger ve ark., 2009).

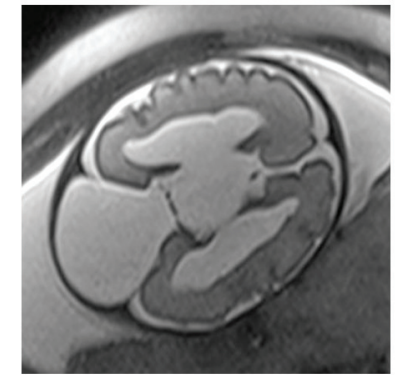

a

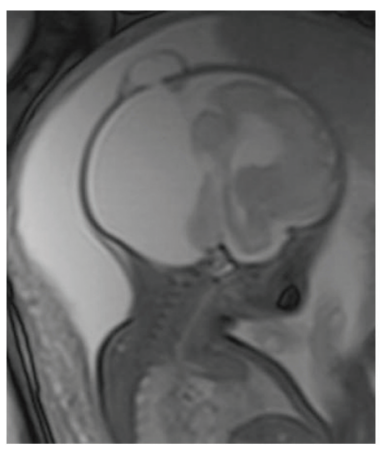

$\mathrm{c}$

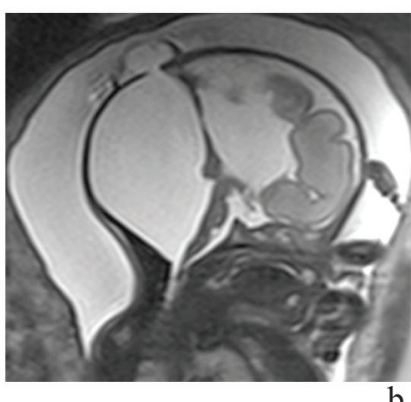

b
Şek. 1. Dandy Walker Malformasyonu, KK Agenezisi, Kranial meningosel, Serebellar vermis agenezisi, Polimikrogyri, İnterhemisferik kist, Kortikal displastik değisiklikler, 30. gh fetus, HASTE sekansinda (a) Aksiyel planda, posterior fossada 4. ventrikülle ilişkili kistik genişleme, orta hatta kavum septum pellucidum (KSP) yokluğu ve interhemisferik kist, lateral ventrikullerde paralel konfigurasyon ve kolposefalik dilatasyon (13-14mm), sağda daha belirgin olmak uzere bilateral lateral ventrikul duvarında irregularite, serebellar vermis agenezisi ve kortikal displastik değisiklikler izlenmekte, Sagital planda HASTE (b) ve TRUFI (c) sekanslarında beyin sapı oluşumlarının posteriordan basılı gorunumde olduğu, tentoryumun superiora yer değistirdiği, paryetooksipital kemikte $6,8 \mathrm{~mm}$ lik defekt varlığı ve kranial meningosel kesesi gorulmekte (d) HASTE sekansında koronal plan kesitlerde KK agenezisi, KSP yokluğu ve interhemisferik kist izlenmektedir. 


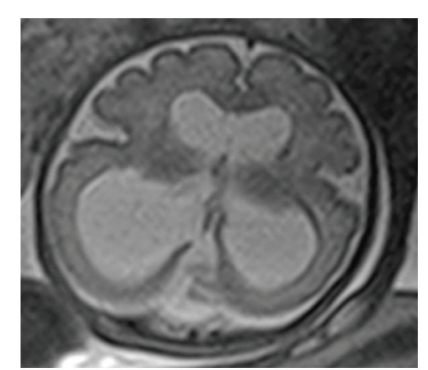

a
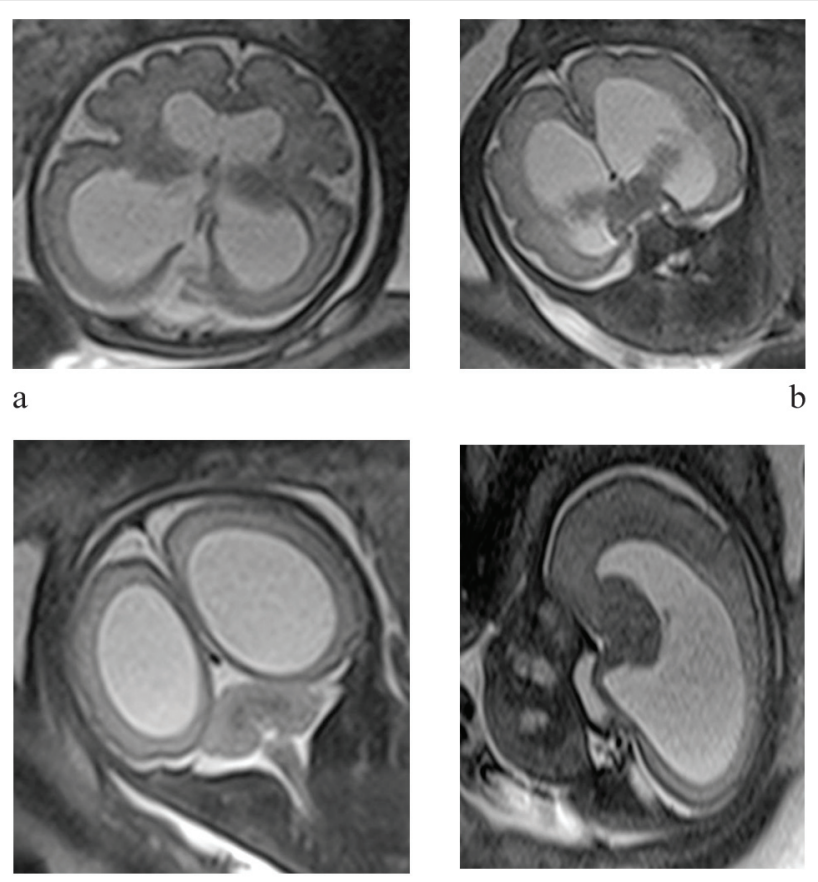

b

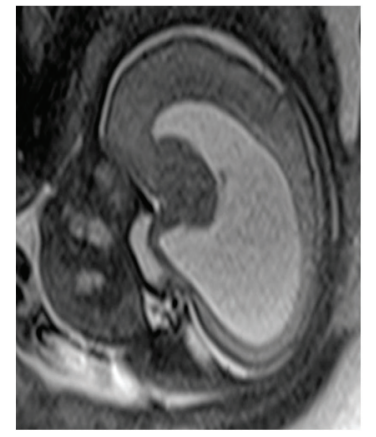

d

Şek. 2. İzole ağır VM, 28. gh fetus, HASTE sekansında (a) Aksiyel planda atrium düzeyinden yapılan ölçümlerde bilateral lateral ventrikül genislikleri $32 \mathrm{~mm}$, (b) ve (c) Koronal plan, serebellumun doğal olduğu ve 4 . ventrikulde dilatasyon olmadığı görülmekte (d) Sagital plan görüntüler

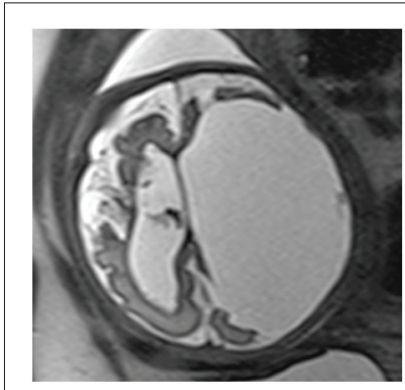

$3 a$

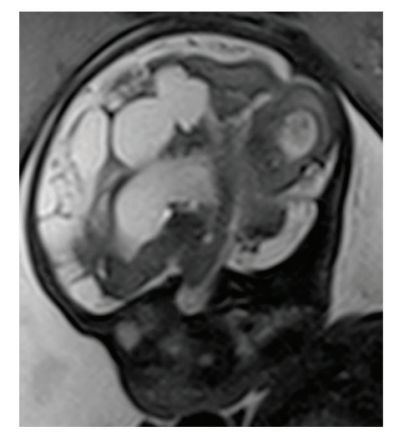

$3 \mathrm{c}$

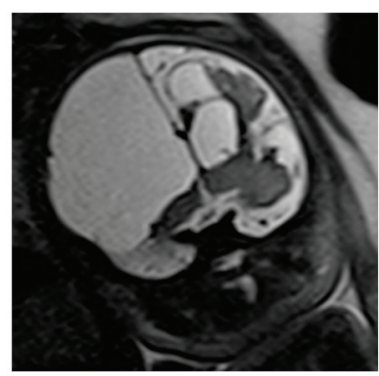

$3 b$

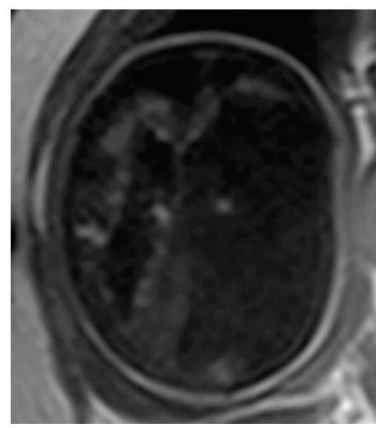

$3 d$

Şek. 3. Ventrikülomegali ön tanıl1, 32. gh fetus, HASTE sekansında (a) Aksiyel planda sağ serebral hemisferi tama yakın dolduran porensefalik kist, serebellar hipoplazi, 4.ventrikülde genişleme, sol lateral ventrikülde VM, irregularite, septasyonlar ve periventrikuler hipointens alanlar, sol serebral kortekste polimikrogyrik değisiklikler, (b) Koronal planda serebellum sağ kesimi basılı görünümde, sağ serebral hemisfer boyutlar1 artmıs (c) Sagital planda sol serebral hemisferdeki kistik ensefalomalazik değisiklikler net bir sekilde izlenmekte, (d) FLASH T1A sekansı aksiyel goruntude HASTE sekansında periventrikuler hipointens izlenen alanların lineer hiperintens kan değerlerine ait olduğu anlasılmaktadır.
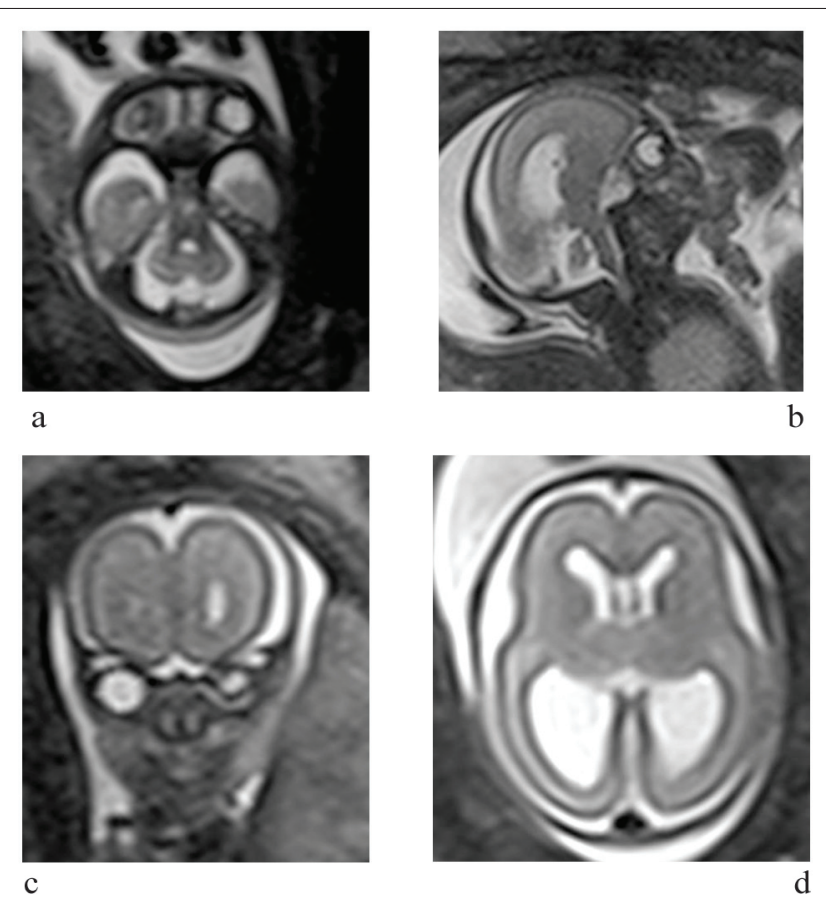

Şek. 4. Mikroftalmi, afaki, 23. gh fetus, HASTE sekansında (a) Aksiyel planda unilateral mikroftalmi ve afaki, diğer goz normal olarak izlenmekte, (b) Sagital planda normal göz ile mikroftalmik bulbus ve afaki, (c) Koronal plan, (d) Ventrikuler düzeyden geçen aksiyel planda bilateral ağır VM izlenmektedir.

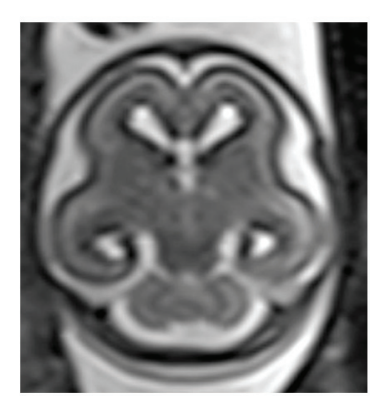

a

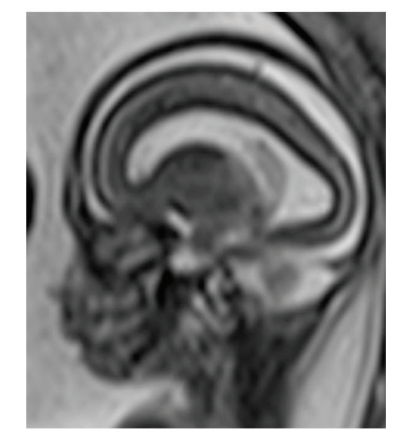

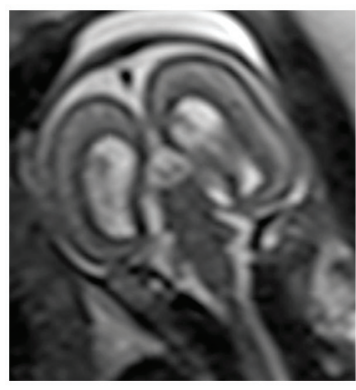

$\mathrm{b}$

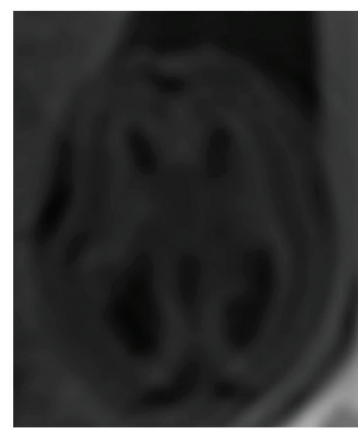

d
Şek. 5. Normal fetal MRG, 20. gh fetus, HASTE sekansında (a) Aksiyel, (b) Koronal, (c) Sagital ve (d) FLASH sekansında T1A goruntuleri.

Buna göre; US'de SSS anomalisi şüphesi olan olguların \% 40'ından fazlasında MRG tanı ve tedaviyi değiştirmiş (Simon ve ark., 2000; Twickler ve ark., 2003), olguların yaklaşık \% 50'sinde US olarak gizli kalan anomaliler (özellikle korpus kallozum agenezisi, sulkasyon anomalisi, periventri- 
küler nodüler heterotopi,serebellar displazi, periventriküler lökomalazi, porensefali, multikistik ensefalomalazi, germinal matriks kanaması ve intraventriküler kanama vb.) fetal MRG ile saptanabilmiştir (Levine ve ark., 1997; 1999; Simon ve ark., 2000; Glenn ve ark., 2003; Whitby ve ark., 2004). Obezite nedeniyle değerlendirilemeyen 4 olguda normal bulgular saptanmıştır (Şek. 5).

VM en sik fetal beyin anomalisi olup prevalans 1000 canlı doğumda 1 (Goldstein ve ark., 1990; Bromley ve ark., 1991) ile bazı yazarlara göre binde 22 olarak değişmektedir (Alagoppa ve ark., 1994). Bizim de çalışmaya aldığımız 80 hastadan 45'ine VM öntanısıyla çekim yapılmış, MRG sonucunda toplam 41 VM saptanmıştır. Robert ve arkadaşları, Cavalcanti ve arkadaşları, Laskin ve arkadaşlarının yaptığı çalışmalarda izole VM oranı \% 50 olarak saptanmıştır (Zimmerman ve Bilaniuk, 2005). Bizim çalışmamızda izole VM $(n=25 / 41) \% 60,9$ oranında bulunmuş olup, son yapılan çalışmalardan daha yüksek oranda saptanmıştır. Bunun nedeni son yıllarda izole hafif VM tanısının artmasıdır.

VM' ye eşlik eden anomalilerin US ile saptanmasında yanlış negatif oranı Patel ve ark. göre; \% 10-25 'tir (Patel ve ark., 1994). Bizim çalışmamızda 41 VM olgusunun 15 'inde MRG ile US'de saptanamayan ek anomaliler saptanmış, US'nin ek anomali saptanmasındaki yanlış negatif oranı $\%$ 36,5 olarak hesaplanmış olup literatür değerlerinden yüksek bulunmuştur. Bunun, US'nin yapan kişiye bağımlı subjektif bir yöntem olmasından kaynaklanabileceği düşünülmüştür.

Manganaro ve ark. yaptığı çalışmada (Manganaro ve ark., 2009), 55 VM olgusunda US ile ek SSS anomalisi saptama oranı $(18 / 55) \% 32,7$ iken MRG ile bu oran $(26 / 55) \%$ 47,3 olarak saptanmış olup hafif VM olgularının (7/26) \% 26,9'unda, orta dereceli VM olgularının (6/13) \% 46,1'inde, ağır VM olgularının (11/16) \% 68,7'sinde MRG ile ek SSS anomalisi saptanmıştır. Bizim çalışmamızda VM olgularının $\% 36,5$ 'unda, hafif VM olgularının \% 34,7'sinde, orta dereceli VM olgularının \% 33,3'ünde ve ağır VM olgularının \% 75 'inde ek SSS anomalisi saptanmıştır.

Ventrikül genişliğinin ölçümünde US'nin doğruluğu sorgulanmaktadır (Simon ve ark., 2000). Simon ve arkadaşları US ile izole VM tanısı konan 3 fetusta, MRG ile ventriküllerin normal olduğunu saptamışlardır; böylece fetal karyotipin belirlenmesi gibi invaziv bir yöntemin endikasyonu ortadan kalkmıştır (Simon ve ark., 2000). Bizim çalışmamızda da 20 hf, 21 hf, 28 hf ve 30 hf 'lik US ile izole VM tanısı konmuş 4 olguda MRG ile ventriküllerin normal olduğu gösterilmiştir.

Ventriküler sistemle ilişkili anomalilere eşlik eden KK agenezisinin fetal MRG ile saptanmasındaki duyarlılığı US ile karşılaştırıldığında çok daha yüksektir (Sonigo ve ark., 1998). Whitby ve arkadaşlarının (Whitby ve ark., 2004) 100 fetus üzerinde yaptıkları çalışmada, 19 olguda US ve MRG'nin aynı tanıyı gösterdiği, 6 olguda ise MRG'nin ek bilgi verdiğini, 29 olguda ise tanıyı değiştirdiğini ama hiçbir olguda US incelemenin MR bulgularına ek bilgi vermediği ve yine hiçbir olguda MR incelemenin yanlış tanı koymadığı bildirilmiştir. Bizim çalışmamızda, ventriküler sistem anomalisine ilaveten KK agenezisi ön tanısı ile fetal MRG çekilen 9 olgunun 6 tanesinde MRG tanıyı doğrularken, 1 tanesinde parsiyel KK agenezisi saptamış, 2 tanesinde KK normal olarak değerlendirilmiştir. Farklı ön tanılarla (Dandy Walker anomalisi, VM, MCM, Meningomyelosel) yollanan ve US ile KK anomalisi saptanmamış 5 olguda fetal MRG ile KK anomalisi saptanmış, bunların 4 tanesi parsiyel 1 tanesi komplet agenezi ile uyumlu olarak raporlanmıştır. KK agenezisi/ hipogenezisi bulunan toplam 12 olgunun 8'inde buna eşlik eden multiple ek anomaliler saptanmış $(\% 66,6)$ olup literatür değerleriyle uyumlu bulunmuştur. Fetal MRG, KK patolojilerini göstermenin yanında eşlik eden anomalileri saptamakta da son derece başarılıdır.

Ayrıca fetal MRG ile holoprozensefali ve şizensefali tiplendirilmesi, bunlara eşlik eden migrasyon anomalilerinin saptanması, özellikle üçüncü trimestrda kraniumun ossifikasyonu nedeniyle değerlendirilemeyen posterior fossa patolojilerinin (Dandy Walker Malformasyonu/Varyant1, retroserebellar araknoid kist, mega sisterna magna ), beyin sap1 ve serebellar komponentlerin optimal değerlendirilmesi mümkün olmaktadır (Laing ve ark., 1994; Sonigo ve ark., 1998; Levine ve ark., 1999; Simon ve ark., 2000; Stazzone ve ark., 2000; Karen ve ark., 2005).

Çalışmamızda prenatal değerlendirmede ilk başvurulan tanı modalitesi olan US tetkiki ile tanı almış veya şüphelenilmiş belli hastalık grubunda fetal MRG tetkikinin etkinliğini ve US'ye olan katkılarını araştırdık US'de VM ve VSİA saptanan ya da şüphelenilen 80 gebeye ait 80 fetusun, fetal MRG tetkikleri retrospektif olarak incelenmiş olup fetal MRG olguların \% 35'inde ek bulgular tesbit etmiş, \% 28,75' inde tanıyı değiştirmiş, \% 36,25'inde tanıyı doğrulamıştır. Bu oranlar göstermektedir ki; prenatal tanıda ilk başvurulacak tanı modalitesi US olmakla beraber US ile VM ve VSİA saptanan ya da şüphelenilen olgularda var olan anomalinin daha detay11 görüntülenebilmesi ve eşlik edebilecek diğer anomalilerin atlanmaması konusunda fetal MRG uygulanmasının gerekliliği açıktır.

\section{KAYNAKLAR}

Alagappan, R., Browning, P.D., Laorr, A., McGahan, J.P., 1994. Distal lateral ventricular atrium. Reevaluation of normal range. Radiology. 405, 193.

Bromley, B., Frigoletto, F.D.J., Benacerraf B.R., 1991. Mild fetal lateral cerebral ventriculomegaly: clinical course and outcome. Ann.J. Obstet. Gynecol. 164, 863-867.

Cardoza, J.D., Goldstein, R.B., Filly, R.A., 1988. Exclusion of fetal ventriculomegaly with a single measurement: the width of the lateral ventricular atrium. Radiology. 169, 711-714.

Cavalcanti, D.P., Salomao, M.A., 2003. İncidence of congenital hidrocephalus and the role of diagnosis. J. Pediatr. 79, 105-106.

Glenn, O.A., Goldstein, R.B., Li, K.C., Young, S.J., Norton, M.E., Busse, R.F., Goldberg, J.D., Barkovich, A.J., 2003. Magnetic resonance imaging of the fetal brain in the evaluation of sonographically suspected abnormalities of the corpus callosum. In: Proceedings of the American Society of Neuroradiology 41st Annual Meeting. Washington, D.C.

Goldstein, R.B., La Pidus, A.S., Filly, R.A., Cardoza, J., 1990. Mild lateral cerebral ventricular dilatation in utero: clinical significance and prognosis. Radiology. 176, 237-242. 
Heiserman, J., Filly, R.A., Goldstein, R.B., 1991. Effect of measurement errors on sonographic evaluation of ventriculomegaly. J. Ultrasound Med. 10, 121-124.

Herman-Sucharska, I., Bekiesinska-Figatowska, M., Urbanik, A., 2009. Fetal central nervous system malformations on MR images. Brain Dev. 31, 185-199.

Laing, F.C., Frates, M.C., Brown, D.L., Benson, C.B., Di Salvo, D.N., Doubilet, P.M., 1994. Sonography of the fetal posterior fossa: false appearance of mega-cisterna magna and Dandy Walker variant. Radiology. 192, 247-251.

Levine, D., Barnes, P.D., Madsen, J.R., Li, W., Edelman, R.R., 1997. Fetal central nervous system anomalies: MR imaging augments sonographic diagnosis. Radiology. 204, 635-642.

Levine, D., Edelman, R.R., 1997. Fast MRI and its application in obstetrics. Abdom. Imaging. 22, 589-596.

Levine, D., Barnes, P.D., Edelman, R.R., 1999. Obstetric MR imaging. Radiology. 211, 609-617.

Levine, D., Barnes, P.D., Madsen, J.R., Abbott, J., Mehta, T., Edelman, R.R., 1999. Central nervous system abnormalities assessed with prenatal MRI. Obstet. Gynecol. 94, 1011-1019.

Levine, D., Barnes, P.D., Madsen, J.R., Abbott, J., Wong, G.P., Hulka, C., Mehta, T., Li, W., Edelman, R.R., 1999. Fetal CNS anomalies revealed on ultrafast MR imaging. A.J.R. 172, 813-818.

Levine, D., 2001. Ultrasound versus magnetic resonance imaging in fetal evaluation. Top Magn. Reson. Imaging. 12, 25-38.

Levine, D., Barnes, P.D., Robertson, R.R., Wong, G., Mehta, T.S., 2003. Fast MR imaging of fetal central nervous system abnormalities. Radiology. 229, 51-61.

Manganaro, L., Savelli, S., Francioso, A., Di Maurizio, M., Coratella, F., Vilella, G., Noia, G., Giancotti, A., Tomei, A., Fierro, F., Ballesio, L., 2009. Role of fetal MRI in the diagnosis of cerebral ventriculomegaly assessed by ultrasonography. Paediatr. Radiol. 114, 1013-1023.

Mc Intosh, R., Merritt, K.K., Richards, M.R., Samuels, M.H., Bellows, M.T., 1954. The incidence of congenital anomalies. A study 5964 pregnancies. Pediatrics. 14, 505.

Messing-Jünger , A.M., Röhrig, A., Stressig, R., Schaper, J., Turowski, B., Blondin, D., 2009. Fetal MRI of the central nervous system: clinical relevance. Childs Nerv. Syst. 25, 165-71.

Myrianthopolus, 1977. Epidemiology of central nervous system malformations. In: Vinken PJ, Bruyn GW, eds. Handbook of Clinical Neurology. Amsterdam: Elsevier. 139-171.

Patel, M.D., Filly, A.L., Hersh, D.R., Goldstein, R.B., 1994. Isolated mild fetal cerebral ventriculomegaly: clinical course and outcome. Radiology. 192,759-764.

Rich, P., Jones, R., Britton, J., Foote, S., Thilaganathan, B., 2007. MRI of the foetal brain. Clin. Radiol. 62, 303-313.

Simon, E.M., Goldstein, R.B., Coakley, F.V., Filly, R.A., Broderick, K.C., Musci, T.J., Barkovich, A.J., 2000. Fast MR imaging of fetal CNS anomalies in utero. A.J.N.R. 21, 1688-1698

Sonigo, P.C., Rypens, F.F., Carteret, M., Delezoide, A.L., Brunelle, F.O., 1998. MR Imaging of fetal cerebral anomalies. Pediatr. Radiol. 28, $212-222$

Oh, K.Y., Kennedy, A.M., Frias, A.E.Jr., Byrne, J.L., 2005. Fetal schizencephaly pre- and postnatal imaging with a review of the clinical manifestations: Radiographics. 25, 647-657.

Stazzone, M.M., Hubbard, A.M., Bilaniuk L.T., Harty M.P., Mever, J.S., Zimmerman, R.A., Mahboubi, S., 2000. Ultrafast MR imaging of the normal posterior fossa in fetuses. Ann. J. Roentgenol. 175, 835-839.

Türk Radyoloji Derneği İzmir Şubesi Eğitim Sempozyumları 2004-2005, Mayıs 2005. Temel Radyoloji Fiziği. İnan Basım, 203.

Twickler, D.M., Reichel, T., Mc Intire, D.D., Magee, K.P., Ramus, R.M., 2002. Fetal CNS ventricle and cisterna magna measurements by magnetic resonance imaging. Ann. J. Obstet. Gynecol. 187, 927-931.

Twickler, D.M., Magee, K.P., Caire, J., Zaretsky, M., Fleckenstein, J.L., Ramus, R.M., 2003. Second-opinion magnetic resonance imaging for suspected fetal central nervous system abnormalities. Ann. J. Obstet. Gynecol. 188, 492-496.

Wang, G.B., Shan, R.Q., Ma, Y.X., Shi, H., Chen, L.G., Liu,W., Qui X.L., Wei, Y.L., Guo, L., Qu, L., Li, H.H., 2006. Fetal central nervous system anomalies: comparison of magnetic resonance imaging and ultrasonography for diagnosis. Chin. Med. J. 119, $1272-1277$.

Whitby, E.H., Paley, M.N., Sprigg, A., Rutter, S., Davies, N.P., Wilkinson, I.D., Griffiths, P.D., 2004. Comparison of ultrasound and magnetic resonance imaging in 100 singleton pregnancies with suspected brain abnormalities. B.J.O.G. 111, 784-792.

Zimmerman, R.A., Bilaniuk, L.T., 2005. Magnetic resonance evaluation of fetal ventriculomegaly associated congenital malformations and lessions. Semin. Fetal Neonatal Med. 10, 429-443. 